\title{
Studi Kinerja 802.11P pada Protokol Ad Hoc On-Demand Distance Vector (AODV) di Lingkungan Vehicular Ad Hoc Network (VANET) Menggunakan Network Simulator 2 (NS-2)
}

\author{
Ilmal Alifriansyah Rahardjo, Radityo Anggoro, dan F.X. Arunanto \\ (ITS) \\ Jl. Arief Rahman Hakim, Surabaya 60111 Indonesia \\ e-mail: onggo@if.its.ac.id
}

Jurusan Teknik Informatika, Fakultas Teknologi Informasi, Institut Teknologi Sepuluh Nopember

\begin{abstract}
Abstrak-Dalam dunia jaringan nirkabel sudah tidak asing dengan salah satu konsep yang memungkinkan komunikasi antar kendaraan (inter-vehicle) dan komunikasi antara kendaraan dengan infrastruktur dis sekitar jalan (vehicle-to-roadside). Konsep ini juga merupakan subset dari dari Mobile Ad-Hoc Network (MANET), yaitu Vehicular Ad-hoc Network (VANET). Pada VANET kendaraan yang ada bertindak sebagai node pada suatu jaringan. VANET terdiri dari banyak node yang juga berfungsi sebagai router. Berbeda dengan MANET, tingkat mobilitas pada VANET lebih tinggi. Tujuan utama dari adanya VANET ini adalah nantinya dapat digunakan untuk menciptakan dan menyediakan aplikasi-aplikasi transportasi untuk mendukung keamanan maupun kenyamanan bagi pengendara. Hal ini tentunya memerlukan implementasi protokol routing yang sesuai dengan karakteristik dari VANET dimana kendaraan-kendaraan yang notabene memiliki dinamika pergerakan node yang tinggi dalam suatu jaringan. Salah satu protokol routing reaktif yang telah teruji dalam VANET adalah routing protokol Ad hoc On-Demand Distance Vector (AODV). Dan pada Studi ini dilakukan analisis performa dari routing protokol Ad hoc On-Demand Distance Vector (AODV) tersebut dengan parameter 802.11p dalam lingkungan VANET. Dari percobaan Studi ini dihasilkan suatu performa bahwa routing protokol AODV dengan parameter 802.11p pada skenario riil mengalami peningkatan nilai rata-rata pada packet deliery ratio dan routing overhead dan mengalami penurunan nilai rata-rata pada delay seiring dengan bertambahnya kepadatan kendaraan dibandingkan dalam skenario grid.
\end{abstract}

Kata Kunci-AODV, VANET, Network Simulator, NS-2, 802.11p.

\section{PENDAHULUAN}

$\mathrm{D}$ EWASA ini perkembangan dunia internet semakin berkembang dengan pesat, mulai digunakan untuk browsing, chatting dan lain sebagainya. Kegiatan tersebut merupakan termasuk suatu aplikasi yang berhubungan dengan proses pengiriman paket data dalam jaringan internet. Berdasarkan hasil survei yang dilakukan oleh Asosiasi Penyelenggara Jasa Internet Indonesia (APJII) dengan Pusat
Kajian Komunikasi Universitas Indonesia (PUSKAKOM UI). Hasil survei menunjukkan bahwa jumlah pengguna internet di Indonesia untuk saat ini telah mengalami peningkatan sebesar $34,9 \%$ dari jumlah seluruh penduduk Indonesia. Jika pada tahun sebelumnya ada sekitar 71,9 juta pengguna internet di Indonesia, maka pada semester pertama 2015 ini jumlah tersebut mencapai sekitar 88,1 juta pengguna. Dengan semakin banyak pengguna internet ini semakin bertambah pula kebutuhan yang diperlukan untuk berkomunikasi antar pengguna dan pasti akan semakin kompleks. Dengan demikian diperlukan sebuah model baru untuk menyediakan layanan jaringan tanpa infrastruktur. Salah satu model baru tersebut adalah Vehicular Ad-hoc Network (VANET) [1]. VANET merupakan konsep subset dari Mobile Ad-Hoc Network (MANET) dimana kendaraan bertindak sebagai node pada jaringan. Mobilitas node yang tinggi merupakan karakteristik dasar VANET yang menyebabkan perubahan yang cepat pada topologi jaringan. Hal ini tentunya memerlukan implementasi protokol routing yang sesuai dengan karakteristiknya di dalam jaringan [2]. Implementasi pada lingkungan VANET dapat dilakukan dengan menggunakan simulasi sehingga penelitian ini dapat dilakukan untuk mempelajari sistem dengan baik. Simulasi dilakukan dengan menggunakan Network Simulator 2 (NS-2). Implementasi ini akan dilakukan analisis performa 802.11p (WAVE) pada protokol routing reactive yaitu Ad hoc OnDemand Distance Vector (AODV).

Dalam Studi ini penulis mengimplementasikan routing protokol AODV dengan parameter 802.11p dalam lingkungan VANET pada network simulator NS-2. Penulis melakukan studi kinerja performa pada routing protokol AODV dengan melakukan simulasi pada skenario yang memiliki jumlah node yang bervariasi. Kemudian dari hasil simulasi tersebut menghasilkan suatu nilai performa yang ditampilkan pada skenario grid dan skenario riil. 


\section{TINJAUAN PUSTAKA}

\section{A. Ad hoc On-Demand Distance Vector (AODV)}

Ad hoc On-Demand Distance Vector (AODV) adalah protokol routing yang termasuk dalam klasifikasi reaktif protokol routing, yang hanya me-request sebuah rute saat dibutuhkan. AODV yang standar ini dikembangkankan oleh C. E. Perkins, E.M. Belding-Royer dan S. Das pada RFC 3561. Ciri utama dari AODV adalah menjaga timer-based state pada setiap node sesuai dengan penggunaan tabel routing. Tabel routing akan kadaluarsa jika jarang digunakan. AODV memiliki route discovery dan route maintenance. Route Discovery berupa Route Request (RREQ) dan Route Reply (RREP). Sedangkan Route Maintenance berupa Data, Route Update dan Route Error (RRER).

AODV memerlukan setiap node untuk menjaga tabel routing yang berisi field :

- Destination IP Address : berisi alamat IP dari node tujuan yang digunakan untuk menentukan rute.

- Destination Sequence Number : destination sequence number bekerjasama untuk menentukan rute.

- Next Hop : 'Loncatan' (hop) berikutnya, bisa berupa tujuan atau node tengah, field ini dirancang untuk meneruskan paket ke node tujuan.

- Hop Count : Jumlah hop dari alamat IP sumber sampai ke alamat IP tujuan.

- Lifetime : Waktu dalam milidetik yang digunakan untuk node menerima RREP.

- Routing Flags : Status sebuah rute; jika up (valid), jika down (tidak valid) atau sedang diperbaiki.

Penemuan jalur (Path Discovery) atau Route Discovery diinisiasi dengan menyebarkan Route Reply (RREP). Ketika RREP menjelajahi node, maka selanjutnya akan secara otomatis menmbuat suatu path baru. Jika sebuah node menerima RREP, maka node tersebut akan mengirimkan RREP lagi ke node atau destination sequence number seperti terlihat pada Gambar 1 dibawah ini.

Pada proses ini, node pertama kali akan mengecek destination sequence number pada tabel routing pada node yang menerima paket tersebut, apakah nilainya lebih besar daripada Route Request (RREQ), jika lebih besar, maka node akan mengirim RREP. Ketika RREP berjalan kembali ke source melalui jalur yang telah diatur, maka paket tersebut akan menngatur kembali jalur rute ke source node dan memperbarui waktu timeout [3].

Dan juga terlihat pada Gambar 2 bahwa jika sebuah link ke hop berikutnya tidak dapat dideteksi dengan metode penemuan rute, maka link tersebut akan diasumsikan putus dan Route Error (RERR) akan disebarkan ke node tetangganya. Dengan demikian sebuah node bisa menghentikan pengiriman data melalui rute ini atau meminta rute baru dengan menyebarkan RREQ kembali.

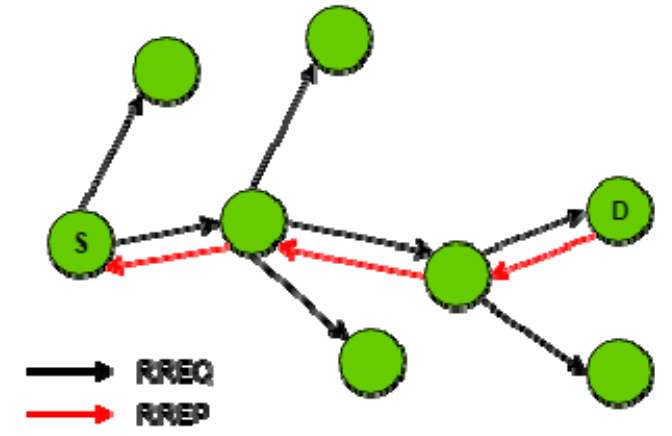

Gambar 1. Mekanisme Penemuan Rute (Route Discover).
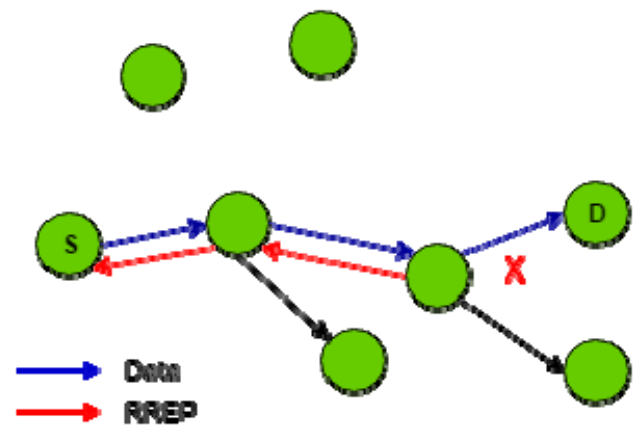

Gambar 2. Mekanisme Pemrosesan Data (Route Update) dan Route Error

\section{B. Network Simulator 2 (NS-2)}

Network Simulator 2 (NS-2) adalah suatu interpreter yang object-oriented, dan discrete event-driven yang dikembangkan oleh University of California Berkeley dan USC ISI sebagai bagian dari projek Virtual Internet Testbed (VINT) [4]. Network Simulator ini menjadi salah satu alat simulasi yang sangat berguna untuk menunjukkan simulasi jaringan melibatkan Local Area Network (LAN), Wide Area Network (WAN), dan dengan berkembangnya zaman berkembang pula fungsi dari alat simulasi ini, yaitu selama beberapa tahun belakangan ini alat simulasi ini melibatkan pada jaringan nirkabel (wireless) serta pada jaringan ad hoc. Adapun beberapa keuntungan menggunakan Network Simulator sebagai alat simulasi pembantu analisi dalam riset, antara lain adalah Network Simulator ini dilengkapi dengan tools validasi yang digunakan untuk menguji kebenaran pemodelan suatu sistem. Secara default, semua pemodelan akan dapat melewati proses validasi ini, seperti media, protokol dan komponen jaringan yang lengkap dengan perilaku trafiknya sudah disediakan pada library Network Simulator. Versi terbaru dari NS-2 adalah ns-2.35 yang dirilis pada tahun 2011.

\section{802.11p - Wireless Access Vehicular Environments (WAVE)}

Untuk memanfaatkan potensi yang ada pada sistem komunikasi antar kendaraan, saat ini IEEE sedang mengembangkan suatu perubahan standar IEEE 802.11p atau yang biasa disebut dengan WAVE (Wireless Access Vehicular Environments [13]. WAVE merupakan penyempurnaan standar IEEE 802.11 yang diperlukan untuk mendukung 
pengaplikasian ITS (Intelligent Transportation Systems). WAVE juga merupakan pengembangan sistem IEEE 802.11a dengan memperkenalkan physical layer dan MAC layer yang dapat meningkatkan sistem operasi dan aplikasi keselamatan dengan memberikan tingkat latency rendah. WAVE sendiri beroperasi pada band $5.9 \mathrm{GHz}$ dengan menggunakan sistem multiplexing OFDM (Orthogonal Frequency Division Multiplexing) dan dapat mencapai kecepatan pentransmisian data antara 6 - 27 Mbps. WAVE terdiri dari tujuh channel pada frekuensi $10 \mathrm{MHz}$ yang dari satu control channel dan enam service channel pada bandwidth $5.9 \mathrm{GHz}$. Service channel digunakan untuk public safety dan private service, sedangkan control channel digunakan sebagai referensi channel untuk membangun link komunikasi antara RSU (Road - Side Unit) dan OBU (On - Board Unit). Control channel digunakan oleh OBU dan RSU untuk broadcast application service, warning message dan safety status message. Dari penjelasan di atas dapat diketahui bahwa aplikasi utama dari IEEE 802.11p adalah untuk sistem komunikasi antar kendaraan dengan sistem komunikasi yang digunakan adalah DSRC (Dedicated Short Range Communication). Pada Studi ini penulis menguji kinerja dan performa dari WAVE ini pada routing protocol AODV menggunakan NS-2.

\section{Vehicular Ad hoc Network (VANET)}

Vehicular Ad hoc Network (VANET) adalah sebuah jaringan terorganisir yang dibentuk dengan menghubungkan kendaraan dan RSU (Roadside Unit) disebut Vehicular Ad Hoc Network (VANET) dan RSU lebih lanjut terhubung ke jaringan backbone berkecepatan tinggi melalui koneksi jaringan. Kepentingan peningkatan baru-baru ini telah diajukan pada aplikasi melalui V2V (Vehicle to Vehicle) dan V2I (Vehicle to Infrastructure) komunikasi, dimana bertujuan untuk meningkatkan keselamatan mengemudi dan manajemen lalu lintas sementara menyediakan pengemudi dan penumpang dengan akses internet.

Dalam Studi ini penulis akan mengimplementasikan 802.11p pada routing protocol AODV dan menguji kinerja dalam lingkungan VANET.

\section{DESAIN DAN PERANCANGAN}

\section{A. Deskripsi Umum}

Pada Studi ini akan dilakukan implementasi dan analisis dari $802.11 \mathrm{p}$ pada routing protocol AODV pada NS-2. Diagram rancangan simulasi dapat dilihat pada Gambar 3. Dimana terdapat 2 (dua) jenis skenario yang digunakan sebagai perbandingan pengukuran lalu lintas kota Surabaya, yaitu skenario grid dan skenario riil. Pada skenario grid peta dibuat dengan bantuan aplikasi SUMO. Sedangkan dalam skenario riil peta yang diambil langsung keadaan saat pengambilan menggunakan OpenStreetMap dengan bantuan editor JOSM. Setelah file peta sudah berbentuk, dilakukan simulasi lalu lintas dengan SUMO. Hasil simulasi SUMO digunakan untuk mencari kinerja dari 802.11p pada simulasi protokol AODV pada NS-2. Kemudian hasil simulasi dari NS2 dianalisis dengan menggunakan skrip AWK untuk menghitung metrik analisis berupa routing overhead, packet delivery dan average end-to-end delay. Perhitungan metrik analisis bertujuan untuk mengukur performa dari protokol AODV untuk melihat performa dari 802.11p.

\section{B. Perancangan Metrik Analisis}

Berikut ini adalah perancangan beberapa metrik yang akan dijadikan analisis dalam Studi ini. Dimulai dari Packet Delivery Ratio (PDR), Average End-to-End Delay dan Routing Overhead (RO). Nilai dari PDR didapat dari perbandingan jumlah paket data yang dikirim dengan jumlah

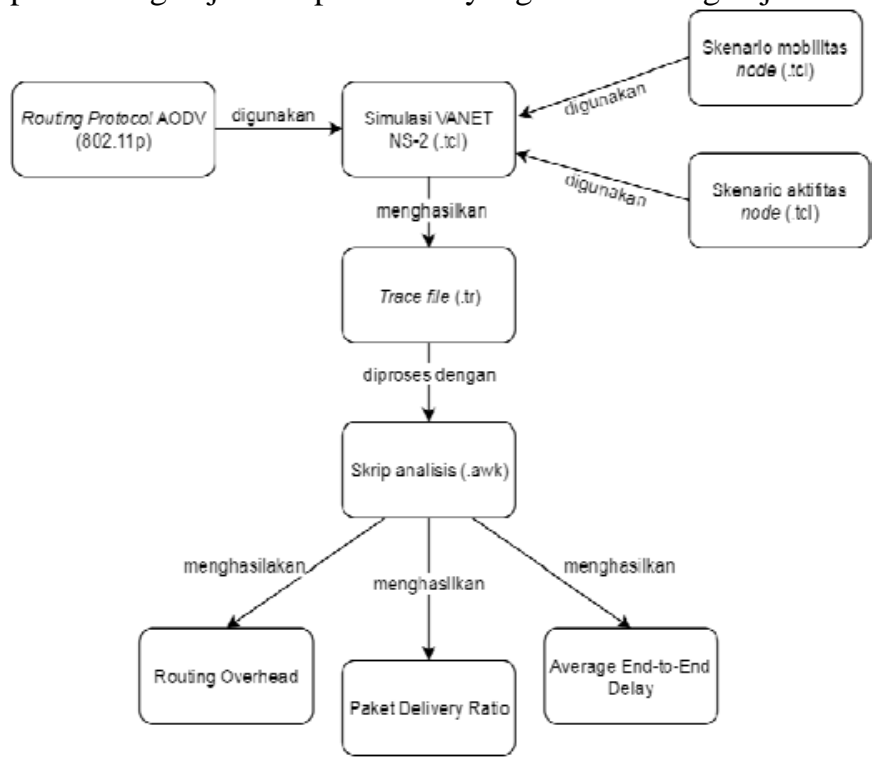

Gambar 3. Diagram Alur Rancangan Simulasi.

paket data yang diterima. Packet delivery ratio dihitung menggunakan Persamaan 3.3, di mana received adalah jumlah paket data yang diterima dan sent adalah jumlah paket data yang dikirim.

$$
P D R=\frac{D a t a_{\text {reoehued }}}{D a t r_{\text {sent }}}
$$

Average end-to-end delay merupakan waktu rata-rata dari setiap paket ketika sampai di tujuan. Semua paket, termasuk delay yang dikarenakan oleh paket routing, ini juga akan diperhitungkan dalam memperoleh nilai akhir. Paket yang akan dimasukkan ke dalam perhitungan hanya paket yang berhasil sampai tujuan. Average end-to-end delay dihitung menggunakan Persamaan 3.2, di mana $i$ adalah nomor paket

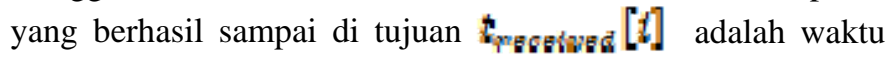
ketika paket $i$ dikirim, sedangkan $t_{\text {gent }}[t]$ adalah waktu ketika paket $i$ diterima dan pktCounter adalah jumlah paket yang berhasil sampai di tujuan. 


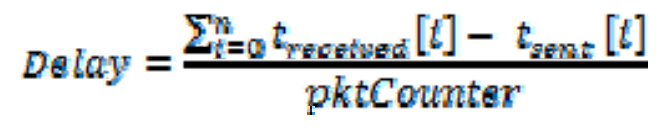

Routing overhead merupakan jumlah paket routing control yang ditransmisikan selama simulasi terjadi. Paket kontrol yang dihitung adalah jumlah Route Request (RREQ), Route Reply (RREP) dan Route Error (RRER). Rumus dari routing overhead dapat dilihat pada Persamaan 3.1.

$$
R Q=R R E Q_{\text {semt }}+R R E P_{\text {sent }}+R R E R_{\text {sent }}
$$

\section{IMPLEMENTASI}

\section{A. Implementasi Skenario Grid dan Skenario Riil}

Pada skenario grid ini dijelaskan bagaimana skenario yang digunakan untuk membuat suatu rute yang berbentuk seperti jala-jala atau grid dengan bantuan tool netgenerate yang telah disediakan oleh SUMO. Skenario grid ini dibuat dengan panjang jalan 200 meter dan luas peta pada skenario grid ini adalah 1200 meter x $1200 \mathrm{~m}$. Jumlah ujung persimpangan antara jalan vertikal dan horizontal sebanyak 6 ujung $\mathrm{x} 6$ ujung. Kecepatan kendaraan yang diperbolehkan untuk melintasi jalan pada skenario ini diatur dengan kecepatan maksimal $15 \mathrm{~m} / \mathrm{s}$. Pada skenario riil parameter sama dengan skenario grid, hanya sedikit berbeda dalam pemakaian peta. Peta yang digunakan skenario riil adalah peta asli dan berkestensi file (.osm), dan berbeda luas, pada peta skenario riil luas peta adalah 1200 meter x 800 meter.

\section{B. Implementasi Network Skenario 2}

Pada implementasi ini dilakukan penggabungan antara hasil skenario grid dan skenario riil berupa file (mobility.tcl) dengan skrip TCL dari kode NS-2 yang diberikan parameterparameter untuk selanjutnya dilakukan percobaan simulasi VANET pada NS-2. Berikut parameter simulasi perancangan sistem VANET yang dapat dilihat pada Tabel 1.

Tabel 1.

Keterangan Parameter dan Spesifikasi pada Simulasi NS-2.

\begin{tabular}{lll}
\hline \hline No & \multicolumn{1}{c}{ Parameter } & \multicolumn{1}{c}{ Spesifikasi } \\
\hline 1 & Network simulator & NS-2.35 \\
& Routing protocol & AODV \\
3 & Area simulasi & $1200 \mathrm{~m} \times 1200 \mathrm{~m}(\mathrm{grid})$ \\
4 & Waktu & $1200 \mathrm{~m} \times 800 \mathrm{~m}(\mathrm{riil})$ \\
5 & Radius transmisi & 360 detik \\
6 & Agen & Constant Bit Rate \\
7 & Source/Detination & Stationary \\
8 & Jumlah kendaraan & 50, 100, 150, 200 \\
\hline \hline
\end{tabular}

\begin{tabular}{lll}
\hline \hline 9 & Kecepatan statis & $15 \mathrm{~m} / \mathrm{s}$ \\
10 & Packet Rate & $2 \mathrm{kB} / \mathrm{s}$ \\
11 & Packet Interval & 1 paket/detik \\
12 & Ukuran Paket & 512 Bytes \\
13 & Protokol MAC & IEEE 802.11p \\
14 & Model Propagasi & Two-ray Ground \\
\hline \hline
\end{tabular}

\section{UJI COBA DAN ANALISIS HASIL}

Uji coba ini dilakukan dengan menggunakan sebuah komputer dan dalam lingkungan yang dibatasi. Berikut ini adalah spesifikasi perangkat dan lingkungan yang digunakan dalam simulasi ini.

- CPU Intel (R) Core TM i3-2130 CPU @3.40GH x 4.

- Sistem Operasi Linux Ubuntu 12.04 LTS 32-bit.

- Memori 3.8 GB.

- Harddisk 500 GB.

- SUMO versi 0.26 .0

- JOSM versi 11223

- Network Simulator ns2.35

Trace file hasil menjalankan program skenario grid dan skeanrio riil ini kemudian dianalisis nilai PDR, Delay dan ROnya dengan script masing-masing awk_PDR, awk_DLY, awk_RO ini merupakan proses awk. Adapun nilai dari PDR setelah simulasi dan dengan perhitungannya, didapatkan nilai seperti pada Tabel 2 dan Gambar 4.

Berdasarkan data tersebut, dapat dilihat bahwa pada skenario riil nilai rata-rata PDR lebih tinggi dibandingkan dengan skenario grid. Pada jumlah node 50, nilai PDR pada skenario riil memiliki 4\% lebih baik dibandingkan pada skenario grid. Pada jumlah node 100 dan 150, pada skenario riil nilai PDR naik ke angka 7,7\% hingga 8,5\% lebih baik dibandingkan dengan skenario grid. Dan pada jumlah node tertinggi, yaitu 200, pada skenario riil nilai PDR naik lagi ke angka 11,4\% lebih baik dibandingkan dengan skenario grid. Banyaknya jumlah node yang pada skenario grid dan skenario riil sama-sama berpengaruh terhadap nilai PDR. Terbukti dari jumlah kepadatan rendah, 50 node, hingga kepadatan paling tinggi, 200 node, nilai PDR dari kedua skenario sama-sama meningkat.

Tabel 2.

Hasil Perhitungan Rata-rata PDR pada Skenario Grid dan Skenario Riil.

\begin{tabular}{cccc}
\hline \hline $\begin{array}{c}\text { Jumlah } \\
\text { Node }\end{array}$ & $\begin{array}{c}\text { Skenario Grid } \\
\mathbf{( \% )}\end{array}$ & $\begin{array}{c}\text { Skenario Riil } \\
\mathbf{( \% )}\end{array}$ & Perbedaan (\%) \\
\hline $\mathbf{5 0}$ & 70,7 & 74,7 & 4 \\
$\mathbf{1 0 0}$ & 73,5 & 81,2 & 7,7 \\
$\mathbf{1 5 0}$ & 80,2 & 88,7 & 8,5 \\
$\mathbf{2 0 0}$ & 88,3 & 99,7 & 11,4 \\
\hline \hline
\end{tabular}




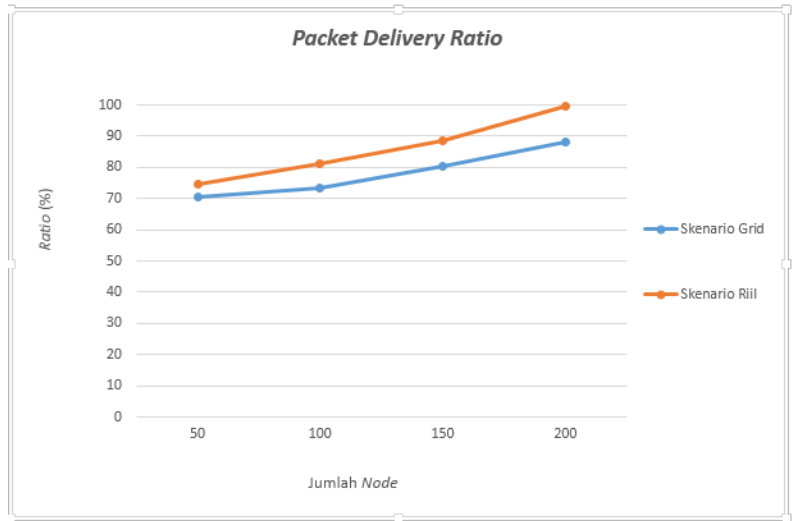

Gambar 4. Grafik PDR pada Skenario Grid dan Skenario Riil.

Namun pada skenario riil nilai PDR sedikit lebih meningkat dibandingkan dengan skenario grid. Hal ini disebabkan perbedaan jumlah paket RREQ dari AODV yang tersebar dalam jaringan. Semakin banyak paket RREQ yang tersebar, maka semakin banyak pula kemungkinan rute yang akan terjadi. Karena pada skenario riil rute yang ada lebih bervariasi dalam pencarian rute karena berbentuk asimetris dibandingkan dengan skenario grid yang lebih simetris dan pencarian rute yang lebih statis.

Selanjutnya adalah nilai dari Delay setelah dilakukan simulasi dapat dilihat pada Tabel 3 dan Gambar 5.

Berdasarkan data tersebut, dapat dilihat bahwa pada skenario riil nilai rata-rata Delay pada kepadatan awal dimana jumlah node masih 50, nilai Delay jauh lebih tinggi hingga memperoleh selisih 0,237 detik dibandingkan dengan skenario grid. Namun pada kondisi dengan jumlah node 100, nilai Delay turun drastis hingga selisih dengan skenario grid berkurang menjadi hanya 0,036 detik saja. Namun seiring bertambahnya kepadatan kendaraan dalam skenario riil, yaitu pada jumlah node 150 hingga 200, nilai Delay ikut naik menjadi 0,076 hingga 0,197 detik, namun kali ini lebih rendah dibandingkan dengan skenario grid. Pada kepadatan rendah, AODV yang ada pada skenario riil memerlukan waktu yang lebih lama untuk melakukan proses route discovery. Ini karena rute dari skenario riil yang lebih bervariasi dari skenario grid yang selalu sama di setiap $200 \mathrm{~m}$, berbeda dengan skenario riil yang setiap jalan mempunyai panjang yang berbeda-beda.

Adapun tren delay yang semakin meningkat pada skenario grid ketika jumlah node semakin banyak ini dikarenakan selain AODV terlalu lama dalam melakukan proses route discovery,

Tabel 3.

Hasil Perhitungan Rata-rata Delay pada Skenario Grid dan Skenario Riil.

\begin{tabular}{cccc}
\hline \hline $\begin{array}{c}\text { Jumlah } \\
\text { Node }\end{array}$ & $\begin{array}{c}\text { Skenario Grid } \\
\text { (detik) }\end{array}$ & $\begin{array}{c}\text { Skenario Riil } \\
\text { (detik) }\end{array}$ & $\begin{array}{c}\text { Perbedaan } \\
\text { (detik) }\end{array}$ \\
\hline $\mathbf{5 0}$ & 0,450 & 0,687 & 0,237 \\
$\mathbf{1 0 0}$ & 0,455 & 0,491 & 0,036 \\
$\mathbf{1 5 0}$ & 0,654 & 0,578 & 0,076 \\
$\mathbf{2 0 0}$ & 0,921 & 0,724 & 0,197 \\
\hline \hline
\end{tabular}

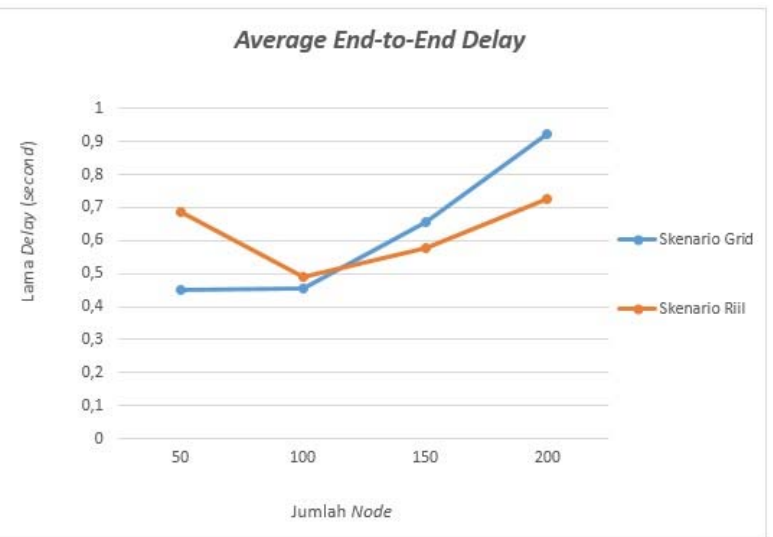

Gambar 5. Grafik PDR pada Skenario Grid dan Skenario Riil.

Tabel 4.

Hasil Perhitungan Rata-rata RO pada Skenario Grid dan Skenario Riil.

\begin{tabular}{cccc}
\hline \hline $\begin{array}{c}\text { Jumlah } \\
\text { Node }\end{array}$ & $\begin{array}{c}\text { Skenario Grid } \\
\text { (paket) }\end{array}$ & $\begin{array}{c}\text { Skenario Riil } \\
\text { (paket) }\end{array}$ & $\begin{array}{c}\text { Perbedaan } \\
\text { (paket) }\end{array}$ \\
\hline $\mathbf{5 0}$ & 2493 & 4314 & 1821 \\
$\mathbf{1 0 0}$ & 4100 & 7062 & 2962 \\
$\mathbf{1 5 0}$ & 7416 & 14688 & 7272 \\
$\mathbf{2 0 0}$ & 16179 & 28368 & 12189 \\
\hline \hline
\end{tabular}

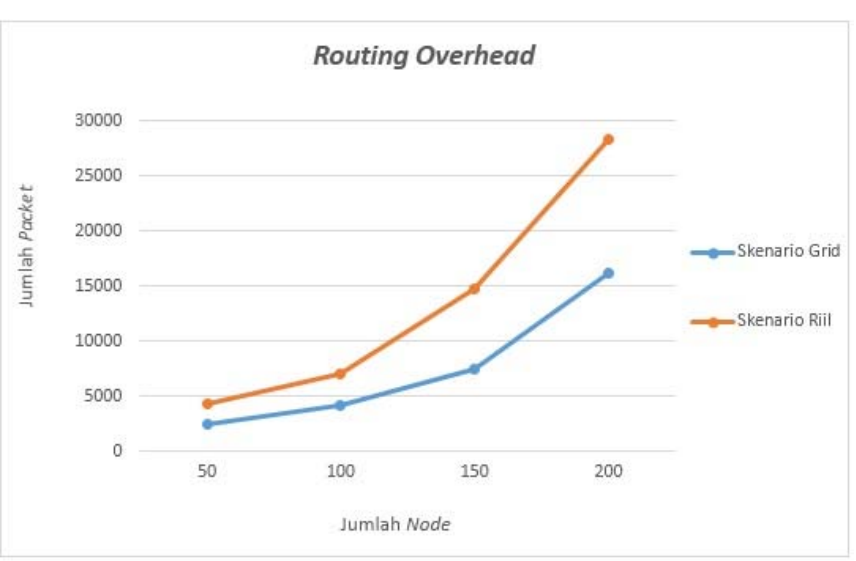

Gambar 6. Grafik Routing Overhead pada Skenario Grid dan Skenario Riil

juga karena terjadi kemacetan jalan di setiap perempatan yang tedapat lalu lintas. Karena AODV melakukan broadcast, buffer paket dari setiap node di sekitar area perempatan menjadi sangat panjang. Berbeda dengan skenario riil yang lebih sedikit memiliki perempatan dan karena jarak antar lampu lalu lintas yang satu dengan yang lain yag bervariasi dan termasuk lebih jauh dibandingkan dengan pada skenario grid.

Dan yang terkahir adalah nilai dari RO setelah dilakukan simulasi dapat dilihat pada Tabel 4 dan Gambar 6.

Berdasarkan data tersebut, dapat dilihat bahwa skenario riil memiliki nilai rata-rata $\mathrm{RO}$ yang lebih tinggi dibandingkan dengan Skenario Grid. Terlihat pada kepadatan awal, dengan jumlah node 50, skenario riil memiliki nilai RO lebih banyak 1821 paket dibandingkan dengan Skenario Grid. Kemudian pada jumlah node 100 hingga node 200, masing-masing dari skenario sama-sama meningkat nilai dari RO. Karena memang pada skenario grid dan skenario riil ini berbeda dalam rute perjalanan pada saat AODV melakukan broadcast, sehingga 
secara otomatis banyak jumlah paket routing yang tersebar dalam jaringan.

Hasil analisis yang dapat ditarik melihat nilai masingmasing metrik diatas menyebabkan beberapa perbedaan. Adapun faktor yang menyebabkan terjadinya perbedaan ini adalah lebih kepada bentuk jalan, luas daerah yang menyebabkan rute yang dilewati node cukup berbeda.

\section{KESIMPULAN DAN SARAN}

Dari hasil uji coba yang telah dilakukan, dapat diambil kesimpulan sebagai berikut:

1. Berdasarkan hasil uji coba perbedaan nilai dari skenario grid dengan skenario riil didapatkan hasil bahwa pada skenario riil protokol AODV memiliki nilai lebih baik daripada dalam skeanrio grid. Seperti dilihat pada nilai rasio perbedaan berikut:

- Nilai PDR dari $4 \%$ pada kepadatan minimum kemudian naik ke $11,4 \%$ pada kepadatan maksimum.

- Nilai Delay dari 65,5\% pada kepadatan minimum kemudian naik hingga $127 \%$ pada kepadatan maksimum.

- Nilai RO dari $11,4 \%$ pada kepadatan minimum dan naik ke angka 57\% pada kepadatan maksimum.

Nilai ini semua tergantung seiring bertambahnya jumlah kepadatan kendaraan pada skenario.

2. Faktor-faktor yang dapat mempengaruhi nilai PDR, Delay dan RO yang dihasilkan dari simulasi dengan skenario grid dan skenario riil adalah:

- Bentuk rute dari masing-masing skenario yang berbeda

- Pergerakan node yang dibuat secara acak.

- Parameter pada masing-masing skenario.

Saran yang dapat diberikan dari hasil uji coba dan evaluasi dari Studi ini untuk pengembangan simulasi kedepan, antara lain:

1. Studi lebih lanjut mengenai pengaruh tipe routing protokol lain (proaktif atau hybird) dengan kepadatan kendaraan yang lebih variatif pada skenario grid dan skenario riil.

2. Dilakukan penambahan model transmisi selain TwoRay-Ground.

3. Dilakukan pengurangan dan penambahan pada kecepatan node maksimal.

4. Diperlukan penyempurnaan sistem lampu lalu lintas agar lebih realistis. Lampu lalu lintas yang diimplementasikan pada Studi ini ditangani sepenuhnya oleh simulator, bukan berdasarkan desain penulis.

\section{DAFTAR PUSTAKA}

[1] A. M. C dan T. C, "A CLUSTER BASED ENHANCEMENT TO AODV FOR INTER-VEHICULAR COMMUNICATION IN VANET," Int. J. Grid Comput. Appl. IJGCA, vol. 3, hal. 41-50, Sep 2012.
[2] "A Noble Routing Protocol for Vehicular ad hoc Networks (VANETs) with Less Routing Overheads," Int. J. Future Gener. Commun. Netw., vol. 7, hal. 23-34, 2014.

[3] B. Ramakrishnan, "Performance Analysis of AODV Routing Protocol In Vehicular Ad-hoc Network Service Discovery Architecture," ARPN J. Syst. Softw., vol. 2, hal. 65-72, Feb 2012.

[4] G. Gautam dan B. Sen, "Design and Simulation of Wireless Sensor Network in NS2," Int. J. Comput. Appl. 0975 - 8887, vol. 113, hal. 1416, Mar 2015.

[5] "DLR - Institute of Transportation Systems - SUMO - Simulation of Urban MObility.” [Daring]. Tersedia pada: http://www.dlr.de/ts/en/desktopdefault.aspx/tabid-9883/16931_read41000/. [Diakses: 18-Jan-2017].

[6] "NETCONVERT - Sumo." [Daring]. Tersedia pada: http://sumo.dlr.de/wiki/NETCONVERT. [Diakses: 01-Jan-2017].

[7] P. TS, "SUMO, Open Street Maps and NS2 - A Real Traffic Simulation.".

[8] K. Thenmozhi dan D. E. Ramaraj, "Routing Overhead in MANET Minimization with Multipath Local Route Discovery Routing Protocol," Int. J. Eng. Trends Technol. IJETT, vol. 13, hal. 144-147, Jul 2014.

[9] P. Rohal, R. Dahiya, dan P. Dahiya, "Study and Analysis of Throughput, Delay and Packet Delivery Ratio in MANET for Topology Based Routing Protocols (AODV, DSR and DSDV)," Int. J. Adv. Res. Eng. Technol., vol. 1, no. II, hal. 54-58, Mar 2013.

[10] “NETGENERATE - Sumo." [Daring]. Tersedia pada: http://sumo.dlr.de/wiki/NETGENERATE. [Diakses: 01-Jan-2017].

[11] “OpenStreetMap,” OpenStreetMap. [Daring]. Tersedia pada: https://www.openstreetmap.org/. [Diakses: 30-Des-2016].

[12] Jagadevi dan D. S. Terdal, "Performance Evaluation of IEEE 802.11p MAC Protocol for VANETs,” Int. J. Sci. Res. IJSR, vol. 4, no. 9, hal. 711-715, Sep 2015. 